\title{
BMJ Global Health Is the cure really worse than the disease? The health impacts of lockdowns during COVID-19
}

Gideon Meyerowitz-Katz (10 , ${ }^{1,2}$ Samir Bhatt, ${ }^{3,4}$ Oliver Ratmann, ${ }^{4}$ Jan Markus Brauner, ${ }^{5}$ Seth Flaxman, ${ }^{4}$ Swapnil Mishra, ${ }^{4}$ Mrinank Sharma, ${ }^{5}$ Sören Mindermann, ${ }^{5}$ Valerie Bradley, ${ }^{5}$ Michaela Vollmer, ${ }^{4}$ Lea Merone, ${ }^{6}$ Gavin Yamey (1) ${ }^{7}$

To cite: Meyerowitz-Katz G, Bhatt $\mathrm{S}$, Ratmann 0 , et al. Is the cure really worse than the disease? The health impacts of lockdowns during COVID-19. BMJ Global Health 2021;6:e006653. doi:10.1136/ bmjgh-2021-006653

Handling editor Seye Abimbola

Received 17 June 2021 Accepted 2 July 2021

\section{Check for updates}

C) Author(s) (or their employer(s)) 2021. Re-use permitted under CC BY-NC. No commercial re-use. See rights and permissions. Published by BMJ.

For numbered affiliations see end of article.

\section{Correspondence to} Dr Gideon Meyerowitz-Katz; gideon.meyerowitzkatz@health. nsw.gov.au

\section{INTRODUCTION}

During the pandemic, there has been ongoing and contentious debate around the impact of restrictive government measures to contain SARS-CoV-2 outbreaks, often termed 'lockdowns'. We define a 'lockdown' as a highly restrictive set of non-pharmaceutical interventions against COVID-19, including either stay-at-home orders or interventions with an equivalent effect on movement in the population through restriction of movement. While necessarily broad, this definition encompasses the strict interventions embraced by many nations during the pandemic, particularly those that have prevented individuals from venturing outside of their homes for most reasons.

The claims often include the idea that the benefits of lockdowns on infection control may be outweighed by the negative impacts on the economy, social structure, education and mental health. A much stronger claim that has still persistently appeared in the media as well as peer-reviewed research concerns only health effects: that there has been a large toll of death and disease attributable directly to government action against COVID-19, a toll larger than that of COVID-19 itself. $^{12}$ The tagline for this claim is that "the cure is worse than the disease". ${ }^{3}$

Here, we consider the claim that lockdowns cause more health harms than COVID-19 by examining their impacts on mortality, routine health services, global health programmes and suicide and mental health. We examine the evidence regarding whether government interventions are to blame for negative health consequences, or whether the lethality and infectiousness of SARS-CoV-2 is as much or more of a driver behind adverse health

\section{Summary box}

Restrictive non-pharmaceutical interventions against COVID-19 (known as 'lockdowns') are associated with health harms

- However, it is challenging to determine whether lockdowns have caused the harms or whether these harms are a direct consequence of the underlying health disaster of the pandemic

- Careful analysis of excess mortality suggests that lockdowns are not associated with large numbers of deaths in places that avoided large COVID-19 epidemics (eg, Australia, New Zealand)

- This evidence must be weighed against the very severe harms caused by COVID-19 itself, as seen for example in Brazil and India

- It is unlikely that government interventions have been worse than the pandemic itself in most situations using data collected to date

impacts. The grave harms from ineffectively mitigated epidemics have been clearly seen in places such as India and Brazil. ${ }^{4}$ Given the benefits from government intervention against COVID-19-slowing spread and preventing COVID-19 deaths-we explore whether the harms of lockdowns are likely to exceed the harms of COVID-19, or if the health harms sometimes attributed to lockdowns may instead be explained directly by the pandemic itself.

\section{SHORT-TERM MORTALITY}

The World Mortality Dataset ${ }^{5}$ is the largest international dataset of all-cause mortality, including many countries that have imposed and not imposed restrictive measures against COVID-19. This project has accumulated excess mortality data on 94 nations from the onset of the pandemic, with the most recent 
data being reported up until mid-2021. The project defines excess mortality as mortality greater than the anticipated modelled number of deaths given existing trends. Using this dataset, we can examine a range of locations that both have and have not imposed lockdowns in terms of their potential damage to population health.

Using these data, we can see that New Zealand and Australia, two countries that imposed several lockdowns and heavy restrictions, experienced no excess mortality during 2020. Similarly, South Korea, Taiwan and Thailand had either no excess mortality or only very modest increases in mortality during lockdown periods when there were few or no COVID-19 cases. Indeed, there are no locations in the dataset that experienced both excess mortality and lockdowns concurrently with low numbers of COVID-19 cases, which is what we would expect if lockdowns were independently causing large numbers of short-term deaths. Conversely, places with few COVID-19 restrictions such as Brazil, Sweden, Russia or at times certain parts of the USA have had large numbers of excess deaths throughout the pandemic.

This pattern indicates that, while there may be multifaceted impacts of intensive government restrictions, including social and economic costs, these are not apparent in short-term increases in mortality. In fact, the World Mortality Dataset appears to show that countries with concerted COVID-19 restrictions have had fewer deaths than in previous years, with the authors estimating that lockdowns may reduce annual mortality by $3-6 \%$ from eliminating influenza transmission alone. ${ }^{5}$ This finding is supported by data from Peru showing that lockdowns are likely to reduce death risks from common sources such as automobile accidents in the short term, resulting in a reduction in the immediate mortality burden when implemented. ${ }^{6}$

The high excess mortality in countries with few restrictions, or less voluntary behaviour change, may not be surprising given the high infectiousness and fatality rate of COVID-19. ${ }^{7-9}$ For example, in Manaus, Brazil, COVID-19 spread was largely unmitigated and as of 15 March 2021 more than $10 \%$ of the entire population aged over 85 years had died of COVID-19. ${ }^{10}$ Similarly, the USA did not impose highly restrictive sets of nonpharmaceutical interventions to contain the spread of SARS-CoV-2 in autumn and winter 2020, and COVID-19 became the leading cause of death in the USA for several months in late 2020 and early 2021. While different places require different measures to stop exponential spread, data from Brazil, the USA and other countries ${ }^{11} 12$ show that moderate containment measures can be insufficient to stop exponential growth of COVID-19 epidemics, in turn leading to an unparalleled mortality burden in the populations affected.

However, the excess mortality data do not refute the position that lockdowns have caused harm in some instances. Comparing the UK and Sweden, for example, does not show a clear benefit of lockdowns in terms of excess mortality (the UK imposed three national lockdowns, yet both countries had very severe impacts). It is impossible to determine from this evidence whether lockdowns have a net benefit, especially given the very high excess mortality in many nations that did pursue such strategies. What is clear is that locations that locked down without experiencing large epidemics of COVID-19 (eg, Australia, New Zealand) did not have large numbers of excess deaths, which provides strong evidence that lockdowns themselves are not sufficient to cause such surges in deaths.

\section{DISRUPTIONS TO HEALTH SERVICES}

Another common claim is that government interventions themselves are responsible for reduced access to and use of healthcare services, which in turn causes harms to health in the long term. However, the available evidence to date does not reliably nor consistently support this assertion. There is clearly an association between large outbreaks of COVID-19, government interventions and reductions in attendance for vital non-COVID health services, and thus the connection between lockdowns and missed contact with health systems is very well established. However, this association may be related to lack of capacity of healthcare services or impacts of the pandemic itself rather than measures taken by governments to reduce cases. It may also simply be caused by the public perception of risk due to fear of the pandemic (ie, people may fear becoming infected by SARS-CoV-2 in healthcare settings and thus they stay home rather than attend health services).

This avoidance of health services can clearly be seen in accident and emergency (A\&E) attendance data from England and emergency department use in Australia. ${ }^{13-15}$ In both countries, emergency activity was suppressed weeks before stay-at-home orders were implemented and remained suppressed well after they were lifted. While this activity was at its lowest level during lockdowns, patients avoided emergency rooms even when they were free to access them. There is also evidence that patients who attend A\&E departments that are overwhelmed by COVID-19 cases have poorer health outcomes. ${ }^{16}$

Moreover, where there are data indicating an association between government interventions and disruptions to healthcare utilisation, it is yet again challenging to disentangle whether the association relates to restrictions intended to prevent COVID-19 cases or the epidemic itself. For example, one study found that there was an increase in out-of-hospital cardiac arrests in England associated with the first wave of COVID-19, but it could not identify whether this was a result of government action or a consequence of SARS-CoV-2 infections. ${ }^{17}$ Another study found that missed cancer screenings in the UK could be associated with a very large increase in cancer deaths, but argued that these missed screenings could be attributed to healthcare staff being reallocated to care for patients with COVID-19 during epidemic peaks or due to government action causing patients to avoid care. ${ }^{18}$ It may be 
that lockdowns tend to disincentivise people from going to routine screenings, but so will overwhelmed health services or a high perceived risk of infection at health facilities; equally, there is a plausible impact on health and well-being directly caused by lockdowns. With current evidence, it is simply not possible to support either causal assertion adequately. This is not to say that the evidence is weak, or insufficient in and of itself, but that untangling the causal implications of government interventions from the pandemic is extremely challenging.

\section{SUICIDE AND MENTAL HEALTH}

In many parts of the world there are substantial lags in reporting of deaths from suicide due to the time it takes for coroners to determine the cause of death. However, despite these lags, there is consistent and robust evidence from many countries that government interventions to control COVID-19 have not been associated with increased deaths from suicide. ${ }^{619-25}$ Indeed, some evidence suggests that the number of deaths from suicide may have dropped in some age groups, particularly children, during the pandemic. ${ }^{25-27}$

While government intervention has not been associated with an increase in deaths from suicide, changes in other mental health conditions are a far more complex issue. There is abundant evidence that mental health has declined in the population since the onset of the pandemic, ${ }^{28-31}$ which may provide evidence that lockdowns cause mental health problems. However, research into this area is fraught with known limitations and confounders, meaning that it is extremely challenging to ascertain whether government intervention causes or is simply associated with mental health declines, perhaps both driven by the underlying confounder of the pandemic itself.

Furthermore, while the relationship between mental health and lockdowns is commonly discussed, the equally important link between large-scale COVID-19 outbreaks and depression and anxiety is often overlooked. The high mortality of COVID-19, resulting burden of bereavement and the accompanying anxiety of individuals regarding the personal risk of infection means that again a false dichotomy exists. There are likely mental health problems, particularly in children, attributable to lockdowns; however, there is an equally plausible burden due to SARS-CoV-2. Missing school clearly affects children's mental health, but so does losing a loved one to COVID-19. ${ }^{32}$ Recent estimates suggest that the number of children who have lost a parent to COVID-19 is extremely high, with a recent paper estimating that 43000 children have lost a parent in the USA. ${ }^{33}$ The same study estimated that 2 million children have lost at least one grandparent to COVID-19. ${ }^{33}$

Generally, the evidence indicates that government interventions against COVID-19 are not associated with increases in suicide figures. Where suicide rates have increased, as in Japan, this was not associated with government action but with large-scale unemployment that occurred well after the government had lifted restrictions and encouraged individuals to return to life largely as normal. ${ }^{34}$ While it certainly appears likely that extended periods of social isolation are problematic for mental health, this can be caused by large outbreaks as well as government action, and is therefore more complex than a simple model of causality. Governments also can and have made attempts to improve mental health, particularly for paediatric populations where schools have been closed, which may have been part of the reason that mental health declines have not generally led to increased rates of suicide.

\section{GLOBAL HEALTH PROGRAMMES}

Surveys conducted by multilateral health agencies found that services for a variety of conditionsincluding HIV, tuberculosis (TB) and malaria-were disrupted by the pandemic. For example, a survey by the Global Fund to Fight AIDS, Tuberculosis and Malaria found that $80 \%$ of HIV programmes and $75 \%$ of $\mathrm{TB}$ programmes reported disruption to service delivery. ${ }^{35}$ By May 2020, childhood vaccination campaigns had been disrupted in 68 countries. ${ }^{36}$ However, these disruptions have been caused by multiple complex direct and indirect consequences of COVID-19, not just stay-at-home orders.

Many low- and middle-income countries such as Brazil, India and South Africa have seen huge waves of COVID-19 that have put enormous strain on their health systems and thus disrupted non-COVID services. In many countries, health workers and health financing that were supposed to be directed at HIV and TB prevention and treatment were redirected to COVID-19 testing and treatment. ${ }^{37}$ For example, a survey by the Stop TB Partnership of 20 countries with a high burden of TB found that at least $40 \%$ of national TB programmes were using TB facilities (hospitals and dispensaries) for the COVID-19 response.$^{38}$ Lockdowns could of course have contributed to disruptions. For example, a study by South Africa's National Institute for Communicable Diseases found that, during South Africa's first lockdown, ТВ testing volumes and positive diagnoses of TB fell even though testing capacity was maintained. ${ }^{39}$ The authors suggest that restrictions on public transport could explain this finding. If South Africa had not locked down at this point, would TB testing volumes have been maintained? Evidence from elsewhere in the globe suggests not-for example, a recent UN report indicated that the country with the greatest reduction in TB testing in 2020 was Indonesia, which also had one of the least restrictive responses to COVID-19 of any country in the world. ${ }^{40}$ 
Table 1 Arguments for the proposition that the "cure is worse than the disease" and the key counter arguments

\begin{tabular}{|c|c|c|}
\hline Health domain & Argument & Key counterarguments \\
\hline Short-term mortality & $\begin{array}{l}\text { Lockdowns themselves } \\
\text { caused an increase in short- } \\
\text { term excess mortality (defined } \\
\text { as mortality greater than the } \\
\text { anticipated modelled number of } \\
\text { deaths given existing trends) }\end{array}$ & $\begin{array}{l}\text { Countries that imposed several strict lockdowns without } \\
\text { experiencing large COVID-19 epidemics (eg, Australia, New } \\
\text { Zealand) did not have large numbers of excess deaths. This } \\
\text { provides strong evidence that lockdowns themselves are not } \\
\text { sufficient to cause surges in deaths }\end{array}$ \\
\hline $\begin{array}{l}\text { Disruption to health } \\
\text { services }\end{array}$ & $\begin{array}{l}\text { Lockdowns are directly } \\
\text { responsible for reduced access } \\
\text { to and use of healthcare } \\
\text { services, which in turn causes } \\
\text { harms to health in the long term }\end{array}$ & $\begin{array}{l}\text { The association between large outbreaks of COVID-19, } \\
\text { government interventions and reduced use of non-COVID health } \\
\text { services is well established. However, this association may be } \\
\text { due to healthcare services being redirected to handle COVID-19 } \\
\text { cases or other impacts of the pandemic itself rather than by } \\
\text { lockdowns. In addition, there is evidence that people fear } \\
\text { becoming infected by SARS-CoV-2 in healthcare settings and } \\
\text { thus stay home rather than attend health services }\end{array}$ \\
\hline Suicide and mental health & $\begin{array}{l}\text { Lockdowns have driven } \\
\text { increases in the suicide rate }\end{array}$ & $\begin{array}{l}\text { There is consistent and robust evidence from many countries } \\
\text { that government interventions to control COVID-19 have not } \\
\text { been associated with increased deaths from suicide }\end{array}$ \\
\hline Global health programmes & $\begin{array}{l}\text { Lockdowns have disrupted } \\
\text { services for HIV, TB, malaria } \\
\text { and vaccination programmes }\end{array}$ & $\begin{array}{l}\text { Such service disruptions are well documented, but the evidence } \\
\text { shows that these have been caused by multiple complex direct } \\
\text { and indirect consequences of COVID-19, not just stay-at-home } \\
\text { orders }\end{array}$ \\
\hline
\end{tabular}

So, while there is no doubt that global health programmes have been disrupted, it remains difficult to tease out the relative contributions of the pandemic itself versus the public health measures put in place to curb SARS-CoV-2.

\section{LOCKDOWNS: COSTS AND BENEFITS}

Public health ethicists and practitioners have long known that stringent control measures aimed at reducing disease mortality and morbidity would be accompanied by negative consequences in many sectors of the economy. ${ }^{41}$ These harms are real, multifaceted and potentially long term, and are therefore an important factor for policy makers to consider when choosing which intervention packages to implement. However, this cost-benefit view must also recognise harms caused by large and ongoing epidemics of COVID-19, and it is often extremely difficult to separate the potential impacts of lockdowns from those of the pandemic itself. Most crucially, many harms are not mutually independent; negative consequences arising from interventions are also present during generalised COVID-19 epidemics. Table 1 summarises the key arguments for the proposition that the "cure is worse than the disease" and the counterarguments that we present in this paper.

We do not mean for the conclusion of this paper to be that lockdowns cannot cause any harm. The reality is that whether lockdowns and other government interventions have a net benefit is a challenging question which requires evaluating social, economic and health aspects. Furthermore, the question poses a false dichotomy. Governments were not faced with the choice between the harms of lockdown and the harms of COVID-19, but rather sought to find the means to minimise the impact of both. When looking at secondary health impacts in particular, often the most that it is possible to say is that there are harms associated with both large COVID-19 outbreaks and government interventions to prevent the disease. It is also important to consider voluntary behaviour change, with evidence that some economic and social harms of the pandemic can plausibly be explained by individual responses to rising infection numbers. ${ }^{42}$ The causal relationships are, unfortunately, extremely difficult to untangle.

It is also important to emphasise the health equity perspective in this discussion. There is a strong interrelationship between disadvantage and the risk of death from COVID-19, ${ }^{43}$ and this is also likely to be true of government interventions against the disease. Where possible, governments should provide support for individuals impacted by both COVID-19 and lockdowns because, regardless of whether the disease runs rampant, the human cost will not be insignificant.

While it is difficult to know what harms have been directly caused by lockdowns, what is clear is that government interventions have a strong impact on COVID-19 cases and deaths, ${ }^{1144} 45$ which has become even more pertinent as new, more dangerous variants of the disease have emerged. Moreover, countries such as New Zealand and Australia, which largely avoided large-scale epidemics of COVID-19, have not seen many of the most severe negative impacts that have occurred in other places, including shortterm excess deaths. There is even some evidence that 
greater restrictions against COVID-19 have reduced death rates below the expected range overall. While it is likely that lockdowns do have negative effects, the fact that there are no locations anywhere in the world where a lockdown without large numbers of COVID-19 cases was associated with large numbers of excess deaths shows quite convincingly that the interventions themselves cannot be worse than large COVID-19 outbreaks, at least in the short term.

\section{CONCLUSION}

While there are certainly costs to be expected from intervening against COVID-19-every decision has a cost, after all-the counterfactual of an unmitigated epidemic makes these restrictions far less damaging than some have suggested. These counterfactuals are not hypothetical and have been observed tragically globally. It appears clear from evidence to date that government interventions, even more restrictive ones such as stay-at-home orders, are beneficial in some circumstances and unlikely to be causing harms more extreme than the pandemic itself.

\section{Author affiliations}

${ }^{1}$ Western Sydney Diabetes, Western Sydney Local Health District, Blacktown, New South Wales, Australia

${ }^{2}$ School of Health and Society, University of Wollongong, Wollongong, New South Wales, Australia

${ }^{3}$ Department of Public Health, University of Copenhagen, Kobenhavn, Denmark

${ }^{4}$ Faculty of Medicine, School of Public Health, Imperial College London, London, UK

${ }^{5}$ Oxford Applied and Theoretical Machine Learning (OATML) Group, Department of Computer Science, University of Oxford, Oxford, UK

${ }^{6}$ College of Public Health, Medical and Veterinary Sciences, James Cook University, Townsville, Queensland, Australia

${ }^{7}$ Duke Global Health Institute, Duke University, Durham, North Carolina, USA

Twitter Gavin Yamey @gyamey

Contributors All authors contributed equally to writing, editing, refining and improving the document as well as all literature searching.

Funding S. Bhatt acknowledges funding from the MRC Centre for Global Infectious Disease Analysis (reference MR/R015600/1), jointly funded by the UK Medical Research Council (MRC) and the UK Foreign, Commonwealth \& Development Office (FCDO), under the MRC/FCDO Concordat agreement and is also part of the EDCTP2 programme supported by the European Union. This research was also partly funded by the Imperial College COVID-19 Research Fund. S.bhatt also aknowledges The UK Research and Innovation (MR/V038109/1), the Academy of Medical Sciences Springboard Award (SBF004/1080), The MRC (MR/R015600/1), The BMGF (OPP1197730), Imperial College Healthcare NHS Trust- BRC Funding (RDA02), The Novo Nordisk Young Investigator Award (NNF200C0059309) and The NIHR Health Protection Research Unit in Modelling Methodology. S. Mishra acknowledges funding from the MRC Centre for Global Infectious Disease Analysis (reference MR/R015600/1) and Community Jameel. M.Sharma was supported by the EPSRC Centre for Doctoral Training in Autonomous Intelligent Machines and Systems (EP/S024050/1). S.Mindermann's funding for graduate studies was from 0xford University and DeepMind. G Meyerowitz-Katz acknowledges funding from the NSW state government and Commonwealth of Australia. J.M. Brauner was supported by the EPSRC Centre for Doctoral Training in Autonomous Intelligent Machines and Systems (EP/S024050/1) and by Cancer Research UK. 0. Ratmann acknowledges funding from the Bill \& Melinda Gates Foundation (OPP1175094).

Competing interests None declared.

Patient consent for publication Not required.

Provenance and peer review Not commissioned; externally peer reviewed.

Data availability statement There are no data in this work.
Open access This is an open access article distributed in accordance with the Creative Commons Attribution Non Commercial (CC BY-NC 4.0) license, which permits others to distribute, remix, adapt, build upon this work non-commercially, and license their derivative works on different terms, provided the original work is properly cited, appropriate credit is given, any changes made indicated, and the use is non-commercial. See: http://creativecommons.org/licenses/by-nc/4.0/.

\section{ORCID iDs}

Gideon Meyerowitz-Katz http://orcid.org/0000-0002-1156-9345

Gavin Yamey http://orcid.org/0000-0002-8390-7382

\section{REFERENCES}

1 Sunetra Gupta $\mathrm{CH}$, Kulldorff M, Bhattacharya J. Collateral Global United Kingdom, 2020. Collateral Global Ltd. Available: https:// collateralglobal.org/about

2 Bendavid E, Oh C, Bhattacharya J, et al. Assessing mandatory stayat-home and business closure effects on the spread of COVID-19. Eur J Clin Invest 2021;51:e13484.

3 Tucker J. Small signs of hope that lockdowns could soon end, 2020. American Institute for economic research. Available: https://www. aier.org/article/small-signs-of-hope-that-lockdons-could-soon-end/

4 Buss LF, Prete CA, Abrahim CMM, et al. Three-quarters attack rate of SARS-CoV-2 in the Brazilian Amazon during a largely unmitigated epidemic. Science 2021;371:288-92.

5 Karlinsky A, Kobak D. The world mortality dataset: tracking excess mortality across countries during the COVID-19 pandemic. medRxiv 2021. doi:10.1101/2021.01.27.21250604. [Epub ahead of print: 29 Jan 2021].

6 Calderon-Anyosa RJC, Kaufman JS. Impact of COVID-19 lockdown policy on homicide, suicide, and motor vehicle deaths in Peru. Prev Med 2021;143:106331.

7 Levin AT, Hanage WP, Owusu-Boaitey N, et al. Assessing the age specificity of infection fatality rates for COVID-19: systematic review, meta-analysis, and public policy implications. Eur J Epidemiol 2020;35:1123-38.

8 O'Driscoll M, Ribeiro Dos Santos G, Wang L, et al. Age-specific mortality and immunity patterns of SARS-CoV-2. Nature 2021;590:140-5.

9 Brazeau N, Verity R, Jenks S. Report 34: COVID-19 infection fatality ratio: estimates from seroprevalence. Imperial College London, 2020. https://www.imperial.ac.uk/mrc-global-infectious-disease-analysis/ covid-19/report-34-ifr/

10 SRAG. Banco de Dados de Síndrome Respiratória Aguda Grave. SRAG, 2021. https://opendatasus.saude.gov.br/dataset/bd-srag2021

11 Brauner JM, Mindermann S, Sharma M, et al. Inferring the effectiveness of government interventions against COVID-19. Science 2021;371:eabd9338.

12 Sharma M, Mindermann S, Rogers-Smith C. Understanding the effectiveness of government interventions in Europe's second wave of COVID-19. medRxiv 2021.

13 NHS England. A\&E attendances and emergency admissions 2020-21, 2021. https://www.england.nhs.uk/statistics/statisticalwork-areas/ae-waiting-times-and-activity/ae-attendances-andemergency-admissions-2020-21/

14 Australian Institute of Health and Welfare. Emergency department care activity, 2021. https://www.aihw.gov.au/reports-data/ myhospitals/sectors/emergency-department-care

15 Michaela AC, Vollmer SR, Kont MD. The impact of the COVID-19 epidemic on patterns of attendance at emergency departments in two large London hospitals: an observational study. BMC Health Serv Res 2021. doi:10.21203/rs.3.rs-45465/v1

16 Wilde H, Mellan T, Hawryluk I. The association between mechanical ventilator availability and mortality risk in intensive care patients with COVID-19: a national retrospective cohort study. medRxiv 2021.

17 RashidM, Gale CP, Curzen N, et al. Impact of coronavirus disease 2019 pandemic on the incidence and management of out-of-hospital cardiac arrest in patients presenting with acute myocardial infarction in England. J Am Heart Assoc 2020;9:e018379.

18 Maringe C, Spicer J, Morris M, et al. The impact of the COVID-19 pandemic on cancer deaths due to delays in diagnosis in England, UK: a national, population-based, modelling study. Lancet Oncol 2020;21:1023-34.

19 Coroners Court of Victoria. Coroners Court monthly suicide data report. Victoria, Australia; 2021. https://www.coronerscourt.vic.gov. au/sites/default/files/2021-05/Coroners\%20Court\%20Monthly\% 20Suicide\%20Data\%20Report\%20-\%20April\%202021.pdf 
20 Leske S, Kõlves K, Crompton D, et al. Real-time suicide mortality data from police reports in Queensland, Australia, during the COVID-19 pandemic: an interrupted time-series analysis. Lancet Psychiatry 2021;8:58-63.

21 NSW Health. NSW suicide monitoring system - report 1 - October 2020. New South Wales, Australia: NSW Health, 2020. https:// www.health.nsw.gov.au/mentalhealth/resources/Pages/suicidemonitoring-report-oct-2020.aspx

22 Faust JS, Shah SB, Du C, et al. Suicide deaths during the COVID-19 stay-at-home advisory in Massachusetts, March to May 2020. JAMA Netw Open 2021;4:e2034273-e

23 Qin P, Mehlum L. National observation of death by suicide in the first 3 months under COVID-19 pandemic. Acta Psychiatr Scand 2021;143:92-3.

24 Holland KM, Jones C, Vivolo-Kantor AM, et al. Trends in US emergency department visits for mental health, overdose, and violence outcomes before and during the COVID-19 pandemic. JAMA Psychiatry 2021;78:372-9.

25 John A, Pirkis J, Gunnell D, et al. Trends in suicide during the COVID-19 pandemic. BMJ 2020;371:m4352.

26 Zee-Cheng J, McCluskey CK, Klein MJ, et al. Changes in pediatric ICU utilization and clinical trends during the coronavirus pandemic. Chest 2021. doi:10.1016/j.chest.2021.03.004. [Epub ahead of print: 13 Mar 2021].

27 Ahmad FB, Anderson RN. The leading causes of death in the US for 2020. JAMA 2021;325:1829-30.

28 Adams-Prassl A, Boneva T, Golin M. The impact of the coronavirus lockdown on mental health: evidence from the US. Cambridge Working Papers in Economics, 2020. https://ideas.repec.org/p/hka/ wpaper/2020-030.html

29 Pierce $\mathrm{M}$, Hope $\mathrm{H}$, Ford $\mathrm{T}$, et al. Mental health before and during the COVID-19 pandemic: a longitudinal probability sample survey of the UK population. Lancet Psychiatry 2020;7:883-92.

30 Brodeur A, Clark AE, Fleche S, et al. COVID-19, lockdowns and well-being: evidence from Google trends. J Public Econ 2021;193:104346.

31 Dawel A, Shou Y, Smithson M, et al. The effect of COVID-19 on mental health and wellbeing in a representative sample of Australian adults. Front Psychiatry 2020;11.

32 Verdery AM, Smith-Greenaway E, Margolis R, et al. Tracking the reach of COVID-19 kin loss with a bereavement multiplier applied to the United States. Proc Natl Acad Sci U S A 2020;117:17695-701
33 Kidman R, Margolis R, Smith-Greenaway E, et al. Estimates and projections of COVID-19 and parental death in the US. JAMA Pediatr 2021;175:745-6.

34 Sakamoto $\mathrm{H}$, Ishikane M, Ghaznavi C, et al. Assessment of suicide in Japan during the COVID-19 pandemic vs previous years. JAMA Netw Open 2021;4:e2037378-e

35 The Global Fund. The impact of covid-19 on HIV, TB and malaria services and systems for health: a snapshot from 502 health facilities across Africa and Asia; 2020. https://www.theglobalfund.org/media/ 10776/covid-19 2020-disruption-impact report en.pdf

36 Joseph A. WHO warns millions of children at risk as Covid-19 pandemic disrupts routine vaccinations. STAT News, 2020. https://www.statnews.com/2020/05/22/who-routine-childhoodvaccinations-disrupted-coronavirus/

37 Hillis S, Unwin HJT, Cluver L, et al. Under the radar: global minimum estimates for COVID-19-associated orphanhood and deaths among caregivers during 2020. SSRN 2021.

38 Stop TB Partnership. The TB response is heavily impacted by the COVID-19 pandemic, 2020. http://www.stoptb.org/news/stories/ 2020/ns20 014.htm

39 Ismail N, Moultrie H. Impact of COVID-19 intervention on TB testing in South Africa. National Institute for Communicable Diseases 2020.

40 United Nations 1.4 million with tuberculosis lost out on treatment during first year of COVID-19, 2021. https://news.un.org/en/story/ 2021/03/1087962

41 Institute of Medicine (US) Forum on Microbial Threats. Ethical and legal considerations in mitigating pandemic disease: workshop summary. Washington (DC): Strategies for Disease Containment 2007.

42 International Monetary Fund. World economic outlook, October 2020: a long and difficult ascent, 2020. https://www.imf.org/en/ Publications/WEO/Issues/2020/09/30/world-economic-outlookoctober-2020

43 Khanijahani A, Tomassoni L. Socioeconomic and racial segregation and COVID-19: concentrated disadvantage and black concentration in association with COVID-19 deaths in the USA. J Racial Ethn Health Disparities 2021. doi:10.1007/s40615-021-00965-1. [Epub ahead of print: 19 Jan 2021].

44 Hsiang S, Allen D, Annan-Phan S, et al. The effect of large-scale anti-contagion policies on the COVID-19 pandemic. Nature 2020;584:262-7.

45 Flaxman S, Mishra S, Gandy A, et al. Estimating the effects of non-pharmaceutical interventions on COVID-19 in Europe. Nature 2020;584:257-61. 